\title{
In memory of Dr. Claudio F. Donner
}

Claudio F. Donner suddenly passed away on August 19 of this year. He was one of the most outstanding and skilled scientists in the field of respiratory medicine.

Born in Varese (Italy) in 1948, he graduated in medicine cum laude from the University of Pavia in 1972, achieved the specializations in Occupational Medicine, Physiokinesitherapy, and Respiratory Medicine, and eventually attended for some months the Medical Research Institute directed by Prof. Gordon Cumming in England. From early Eighties and for many years further he was at the head of Pulmonary Division of the Salvatore Maugeri Foundation in Veruno (Novara, Italy). Author of numerous textbooks, at both national and international level, and of numerous original scientific papers mainly in respiratory medicine (more than 207 indexed in

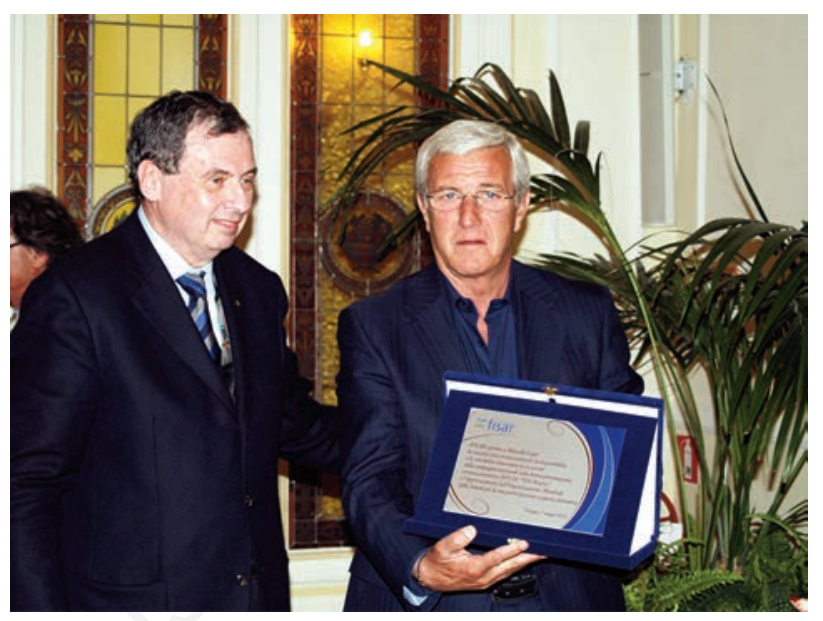

In 2010 in Viareggio during the "Corso Master in Medicina Respiratoria" Dr. Claudio Donner (on the left) rewarded Marcello Lippi, coach of the Italian National Football Club, for his support in favor of the national campaign on COPD "SOS RESPIRO”. PubMed), he was charged with lectureship in several Italian universities. Member of the numerous

Italian and International respiratory Societies, he held the position of Secretary General of European Respiratory Society (ERS) from 1998 to 2004 and President of Italian Association of Ho- spital Pneumologists (AIPO). In 2006, after the foundation of AIMAR (Italian Interdisciplinary Association for Research in Lung Disease), of which he was President from 2006 to 2012 and since 2015 Honorary President, together with some colleagues, among whom the undersigned, he realized the publication and was Co-Editor up to 2016 of Multidisciplinary Respiratory Medicine (MRM), a journal with a particular focus on interdisciplinary research, open to the contribution of all scientists who for various reasons are interested in respiratory medicine. Since then, MRM made great strides and now it occupies a firm position in the international scenery of respiratory journals. On the whole, his interest for the scientific literature and the international research was huge and that's why he was always and up to his last days reviewer of several important scientific publications.

The above mentioned activities are only a few of the numerous achievements Claudio attained in his professional life, always without leaving out his beloved family.

The death of Claudio Donner is a heavy loss for the pneumology at international level and for me also the irrecoverable loss of a dear friend. 